\title{
Haemorrhagic necrosis of small intestine and acute pancreatitis following open-heart surgery
}

\author{
E. H. HORTON, S. K. MURTHY, AND R. M. E. SEAL \\ From Sully Hospital, Glam.
}

Five cases of haemorrhagic necrosis of the small intestine occurring after valve replacement under cardiopulmonary bypass are described. In one case, in addition to the above, there was an unusual complication, namely acute pancreatitis. The possible causes are discussed. The importance of hypotension before, during, or after bypass, or in the post-operative phase, is stressed.

Haemorrhagic necrosis of the small intestine has been described in association with numerous clinical conditions (Berger and Byrne, 1961; Marston, 1962; McGovern and Goulton, 1965). It has also been recorded following open-heart surgery for correction of aortic incompetence (Robertson and Dodds, 1964). Up to 31 January 1967 a total of 168 valve replacements had been carried out at this hospital-78 mitral, 72 aortic, 16 multiple, and 2 tricuspid. Of these, five patients developed haemorrhagic necrosis of the intestine which proved fatal-four following mitral valve replacement and one following aortic valve replacement.

\section{CASE REPORTS}

CASE 1 A housewife aged 40 was admitted in August 1964 for mitral valve replacement. She had had rheumatic fever at the age of 10 , and mitral stenosis was diagnosed at the age of 36 years. In 1960, at the age of 37 , she had a closed mitral valvotomy with the production of slight regurgitation. After initial improvement she gradually deteriorated and required continuous medical treatment for congestive cardiac failure.

In September 1964 the mitral valve was replaced by a Starr-Edwards prosthesis under cardiopulmonary bypass using the Melrose oxygenator (duration 3 hours 50 minutes); perfusion was successful. At the conclusion of bypass cardiac failure was evident, the mean blood pressure falling to $35 \mathrm{~mm}$. $\mathrm{Hg}$ and remaining so for 30 minutes, while the central venous pressure rose to $30 \mathrm{~mm}$. Hg. Supportive measures included tracheostomy and artificial ventilation, and intravenous metaraminol (Aramine) infusion which maintained a systolic blood pressure of $100 \mathrm{~mm}$. $\mathrm{Hg}$ approximately. The patient recovered consciousness but exhibited abdominal distension and oliguria $\stackrel{c}{\stackrel{c}{<}}$ There was progressive circulatory failure and she $\vec{\bullet}$ died 48 hours later.

Post-mortem findings There was slight icterus? and slight bleeding into the tissues of the operation wounds.

The lungs were firm, congested, and oedematous, the right weighing $900 \mathrm{~g}$. and the left $860 \mathrm{~g}$.

The Starr-Edwards valve was incompetent because $\overrightarrow{\vec{O}}$ of an inability of the ball to seat against the rim due to impingement by residual fibrous valve tissue posteromedially. The tricuspid valve cusps were onlyz slightly thickened, but the valve was incompetent to the water test. The right atrium was dilated. The myocardium was generally soft and yellowish in colour.

There was about $12 \mathrm{~cm}$. of ileum darkly congested음 with much blood-stained mucus in the lumen. Other areas of gut appeared normal (Fig. 1).

There was severe chronic venous congestion of the liver and spleen.

The cortex of both kidneys was soft and haemor rhagic.

Histological examination The lungs revealed pul-or monary oedema, in places mimicking hyaline mem- $N$ brane disease, and sparse foci of haemosiderin-ladenN macrophages.

The kidneys showed an extensive tubular necrosis, and many glomeruli contained small, clear, operio spaces containing non-particulate matter, suggesting aळ moderate degree of fat embolism.

The liver showed marked centrilobular venous con- $\square$ gestion with slight fatty change.

The myocardium showed patchy areas of early necrosis with no inflammatory reaction.

The ileum revealed mucosal infarction with no evidence of thrombosis or infarction in the arteries? or veins (Fig. 2). 


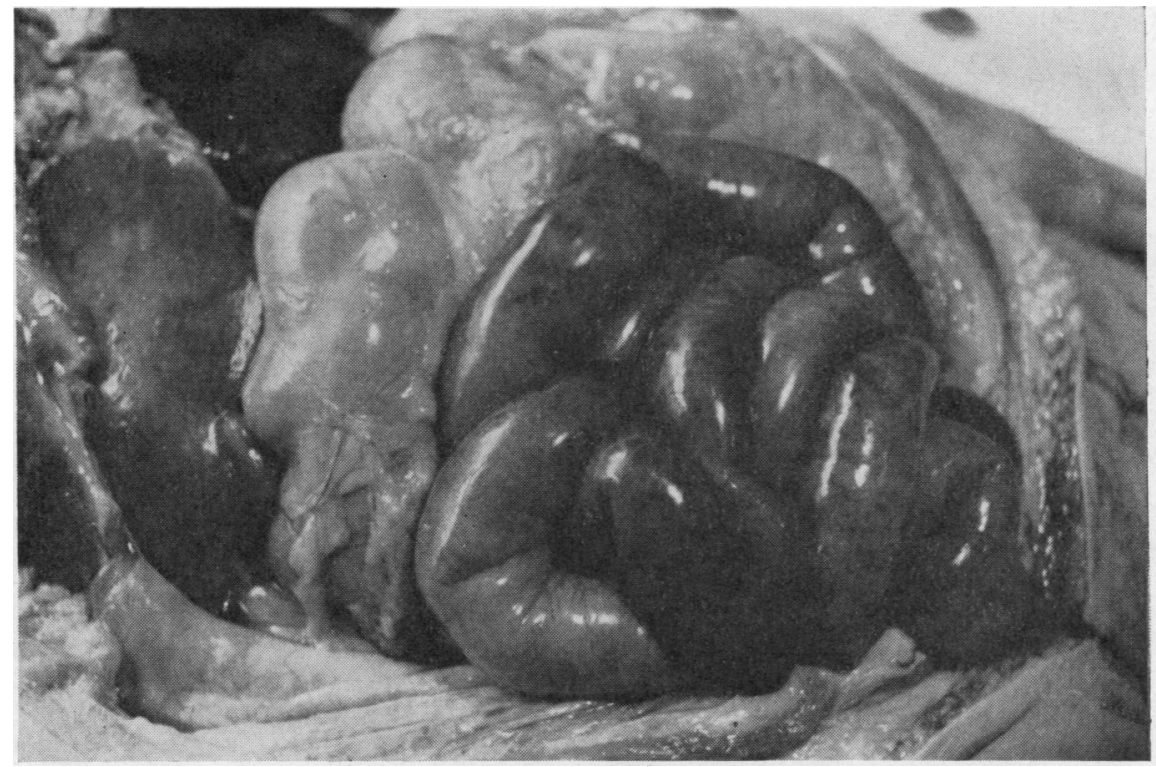

FIG. 1. Small intestine showing areas of discoloration and necrosis.

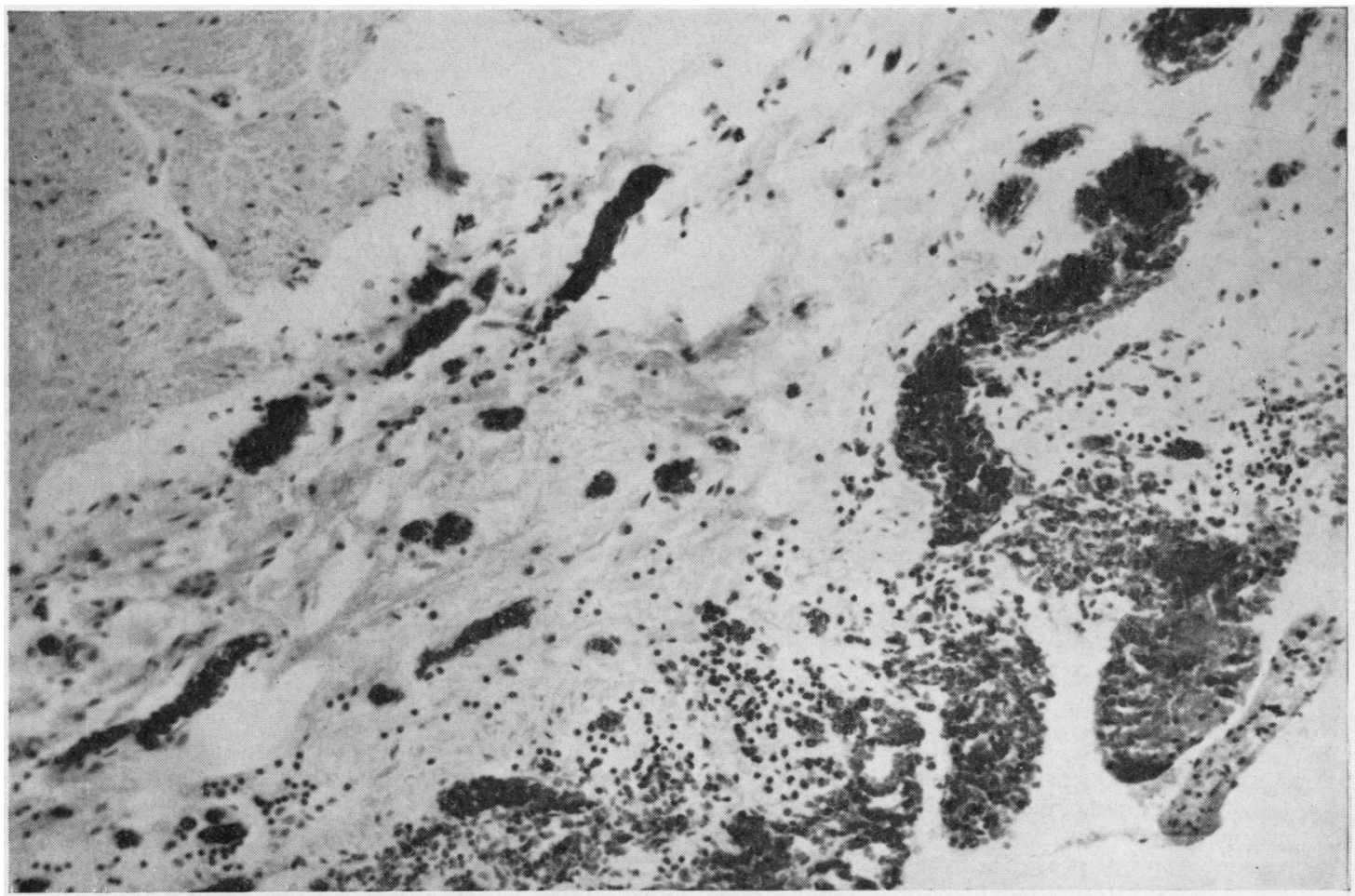

FIG. 2. Small intestine showing haemorrhagic necrosis of mucosa and normal muscle laver. $\times 230$. 
CASE 2 A housewife aged 42 was admitted in November 1964 for mitral valve replacement. She gave a history of rheumatic fever at the age of 12 years. Symptoms of cardiac failure were first noticed at the age of 34 , and investigation showed mitral valve disease with dominant incompetence. She required medical treatment until 1964, when the mitral valve was replaced by a Starr-Edwards prosthesis under cardiopulmonary bypass using the Melrose oxygenator. Perfusion was difficult: the left femoral artery could not be cannulated satisfactorily due to atheromatous changes, and the right femoral artery was finally cannulated with a $3.5 \mathrm{~mm}$. cannula. This was too small to provide an adequate flow, and from the start the perfusion pressure reached only 25-40 mm. $\mathrm{Hg}$ with a high arterial 'line' pressure. Because of the inadequate arterial flow the patient was cooled to $25^{\circ} \mathrm{C}$., but in the later stages of the perfusion (duration 1 hour 30 minutes) a metabolic acidosis developed and persisted thereafter. The administration of one dose of methoxamine failed to elevate the perfusion pressure. However, bypass was concluded satisfactorily, circulation being adequately maintained.

Post-operatively the patient was mechanically ventilated through an endotracheal tube. She recovered consciousness comnletely, and complained of pain in the abdomen at once. The abdomen was noted to be distended and tender. Peripheral circulation was poor, pulses being impalpable, although the central blood pressure was normal. Cardiac arrest, which resisted resuscitation, occurred 24 hours later following an episode of anoxia.

Post-mortem findings Examination revealed that the Starr-Edwards valve was well seated. The left ventricle was slightly dilated and hypertrophied. There was a raw muscular surface where the papillary muscle had been removed and there was slight bruising of the myocardium from internal massage against the prosthesis.

The stomach contained bloodstained fluid and there were several purpuric haemorrhages in the mucosa of the fundus.

A large portion of the ileum was dark purple in colour. The mucosal surface was necrotic and haemorrhagic and the contents frankly haemorrhagic. There was no atheroma nor embolic occlusion of the superior mesenteric artery and no antemortem thrombus was found in the mesenteric vein.

Histological examination revealed haemorrhagic necrosis of the mucosa, the muscular coat appearing normal. The submucosal vessels were considerably dilated.

CASE 3 A housewife aged 40 was admitted for mitral valve replacement in February 1965. She gave a history of rheumatic fever at the age of 15 years. At the age of 35 mitral valve disease with dominant incompetence was proved, following which she required continuous treatment for congestive cardiac failure.
In February 1965 the mitral valve was replaced with a Starr-Edwards prosthesis under cardio- $\frac{7}{0}$ pulmonary bypass using the Melrose oxygenator. The $\frac{C}{\sigma}$ attempted onset of perfusion resulted in sudden par- $\frac{\bar{\sigma}}{\bar{\sigma}}$ tial exsanguination of the patient into the oxygenator $\vec{\nabla}$ due to obstruction in the left femoral artery. with $\varrho$ resultant hypotension (mean blood pressure $30 \mathrm{~mm}$. $\mathrm{Hg}$ ) for 5 minutes. As soon as the patient's blood $\overrightarrow{0}$ volume was restored the blood pressure rose to 50. mm. $\mathrm{Hg}$ (mean). A further attempt at bypass proved $\vec{\omega}$ impossible until the aorta was cannulated, following $\vec{\omega}$ which it was established with a satisfactory flow. $\vec{x}$ Very soon the mean perfusion pressure was $135 \mathrm{~mm}$. $\mathrm{Hg}$. The flow was reduced to $50 \mathrm{ml} / \mathrm{kg} . / \mathrm{min}$. and $\mathrm{\omega}$ the body temperature to $22^{\circ} \mathrm{C}$; the high mean perfusion pressure persisted throughout the perfusion $\vec{\omega}$ (duration 2 hours). No metabolic acidosis occurred $\infty$ and $200 \mathrm{ml}$. of urine were secreted. Bypass was easily 윽 concluded: after closure of the chest ventricular $\rightarrow$ fibrillation occurred, requiring internal defibrillation. $\subseteq$

The patient was ventilated mechanically through an endotracheal tube and was returned to the post- $\vec{\varphi}$ operative ward fully conscious. Abdominal distension was noted and the patient complained of abdominal pain. Tracheostomy was performed on the following day, and shortly after this cardiac arrest occurred, which resisted resuscitation.

Post-mortem findings There was extensive super-융 ficial bruising of the right groin.

The lungs were firm, indurated and oedematous. $\overline{\bar{O}}$ with a moderate number of haemosiderin foci.

The artificial valve was well seated. There was some laceration of the lateral wall of the left ventricle due to massage trauma from the cage of the valve.

There was about $30 \mathrm{~cm}$. of distended, dark, haemor-으 rhagic, apparently infarcted ileum but no evidence of $\underset{x}{\mathfrak{D}}$ atheromatous occlusion of the superior mesenteric $\bar{\sigma}$ artery or thrombotic occlusion of the mesenteric 3 vessels.

There was a retroperitoneal haemorrhage, following adventitial rupture of a dissecting aneurysm of the left femoral up to the common iliac arteries.

There were two 'old' renal infarcts.

Histological examination There was intense congestion with complete necrosis of epithelium but with $\mathrm{F}$ normal muscular coats. There was clumping of red 0 cells with fibrin thrombi in some arterioles.

The kidneys showed slight to moderate tubular damage. There were only occasional fat emboli with no doubly refractile material in the glomerular capillaries.

CASE 4 A housewife aged 61 was admitted for assess- $\frac{0}{0}$ ment in December 1964. She gave a history of rheu- $\frac{\vec{D}}{\mathbb{D}}$ matic fever at the age of 19 years. Symptoms of

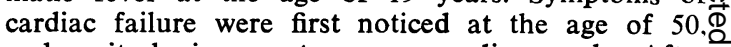
and mitral incompetence was diagnosed. After December 1964 her condition deteriorated despite treatment. 
In April 1965 the mitral valve was replaced by a Starr-Edwards prosthesis under cardiopulmonary bypass using the Melrose oxygenator (duration 3 hours 13 minutes). Perfusion was uneventful for 2 hours, but then blood persistently became sequestered in the patient, and a metabolic acidosis occurred. When perfusion was concluded haemorrhage from the left atrium was prolonged. Eventually haemorrhage was controlled, but during this period hypotension was present despite rapid intra-arterial transfusion.

The patient recovered consciousness in the postoperative ward, but for the first 10 hours after operation hypotension was present in greater or lesser degree, and several doses of epinephrine and metaraminol were given. Hypovolaemia was also present, as evidenced by a central venous pressure of $1 \mathrm{~cm}$. water. Circulatory failure was gradually progressive: continuous blood transfusion failed to elevate the venous pressure, and continuous intravenous epinephrine maintained a mean blood pressure of only $35 \mathrm{~mm}$. $\mathrm{Hg}$. Ventricular fibrillation supervened on the second post-operative day. External defibrillation was accomplished, but as the circulation was quite inadequate despite continuous vasopressor drugs, supportive bypass (femoral vein to femoral artery) was undertaken with a disposable bubble oxygenator. Repeated attempts to end the supportive bypass failed. It was therefore abandoned after 6 hours.

Post-mortem findings There was a small right haemothorax and some bloodstained fluid in the trachea and bronchi. The lungs were somewhat congested with two linear fibrous scars of old healed infarction.

The Starr-Edwards valve was well seated and the left ventricle was moderately dilated with thickening of the chordae and residual valve tissue.

In the abdomen there was a small, straw-coloured ascites. There was a $30-\mathrm{cm}$. length of distended, deeply congested ileum with a fine fibrinous exudate on the peritoneal surface. Another shorter length of ileum was similarly involved. The ileal contents were bloodstained. There were several, small, mucosal haemorrhages of the sigmoid colon, but there was no blood in the lumen. The mesenteric artery was injected with radio-opaque material and radiographs were taken. No obstruction was seen in the major or smaller branches of the artery, and a comparison of the 'infarcted' and neighbouring uninvolved ileum revealed no difference in the vascular pattern.

Histology There was haemorrhagic necrosis of ileal mucosa and a few smaller mucosal vessels contained fibrin thrombi.

There was slight proximal tubular damage. There were occasional fat emboli in the glomerular capillaries.

CASE 5 A housewife aged 56 was admitted for aortic valve replacement in January 1967. She gave a history of progressive exertional dyspnoea and angina of effort for just over one year. There was no history of rheumatic fever. Aortic stenosis with moderate incompetence was proved in April 1966.

In January 1967 the aortic valve was replaced by a Starr-Edwards prosthesis under cardiopulmonary bypass (duration 2 hours) using a Kay-Cross type oxygenator. Perfusion was uneventful. At the conclusion, the heart took over well, maintaining a good circulation. The patient regained consciousness slowly and obeyed simple requests. She was mechanically ventilated through an endotracheal tube. Ten hours later there was sudden hypotension, the systolic pressure falling to just over $100 \mathrm{mg}$. $\mathrm{Hg}$ (the pre-operative pressure was $150 \mathrm{~mm}$. $\mathrm{Hg}$ ) and her level of consciousness deteriorated ; the urinary output decreased, progressing to total renal failure. Slight abdominal distension was noted. The renal failure was treated by the usual means, and a continuous adrenaline drip was started which improved her circulation and level of consciousness. On the first post-operative day tracheostomy was performed and mechanical ventilation was continued. Adrenaline was discontinued after 5 hours, when the blood pressure was maintained around $130 / 80 \mathrm{~mm}$. $\mathrm{Hg}$. But on the fourth postoperative day there was cardiac arrest which resisted all resuscitative measures, including external cardiac massage.

Post-mortem findings The trachea contained much thick, tenacious, bloodstained mucus.

The Starr-Edwards valve was well placed and the coronary orifices were normal. The right coronary artery was small and the large circumflex branch of the left was semi-occluded by calcifying atheroma. The papillary muscles seemed somewhat greenish in colour, suggesting recent necrosis.

The oesophagus was congested and the lower mucosa haemorrhagic; there were a few linear ulcers.

There was a haemorrhagic pancreatitis with areas of fat necrosis in the pancreas and omentum. There was much retroperitoneal haemorrhage on the left side around the kidney and splenic hilum.

There was severe chronic venous congestion of the liver.

The small bowel was distended and there were several segments up to $20 \mathrm{~cm}$. in length, dark and congested, with blood in the lumen.

There were several small, recent, wedge-shaped infarcts of spleen and one small infarct of the left kidney. The cortex of the kidneys was pale.

There were small foci of haemorrhagic necrosis of the cortical grey matter between the parietal and occipital lobes.

Histological examination One section of gut revealed necrosis of the superficial mucosa, the muscle coats and deeper epithelium surviving. There was no thrombotic occlusion of vessels, though the veins were dilated and engorged. 


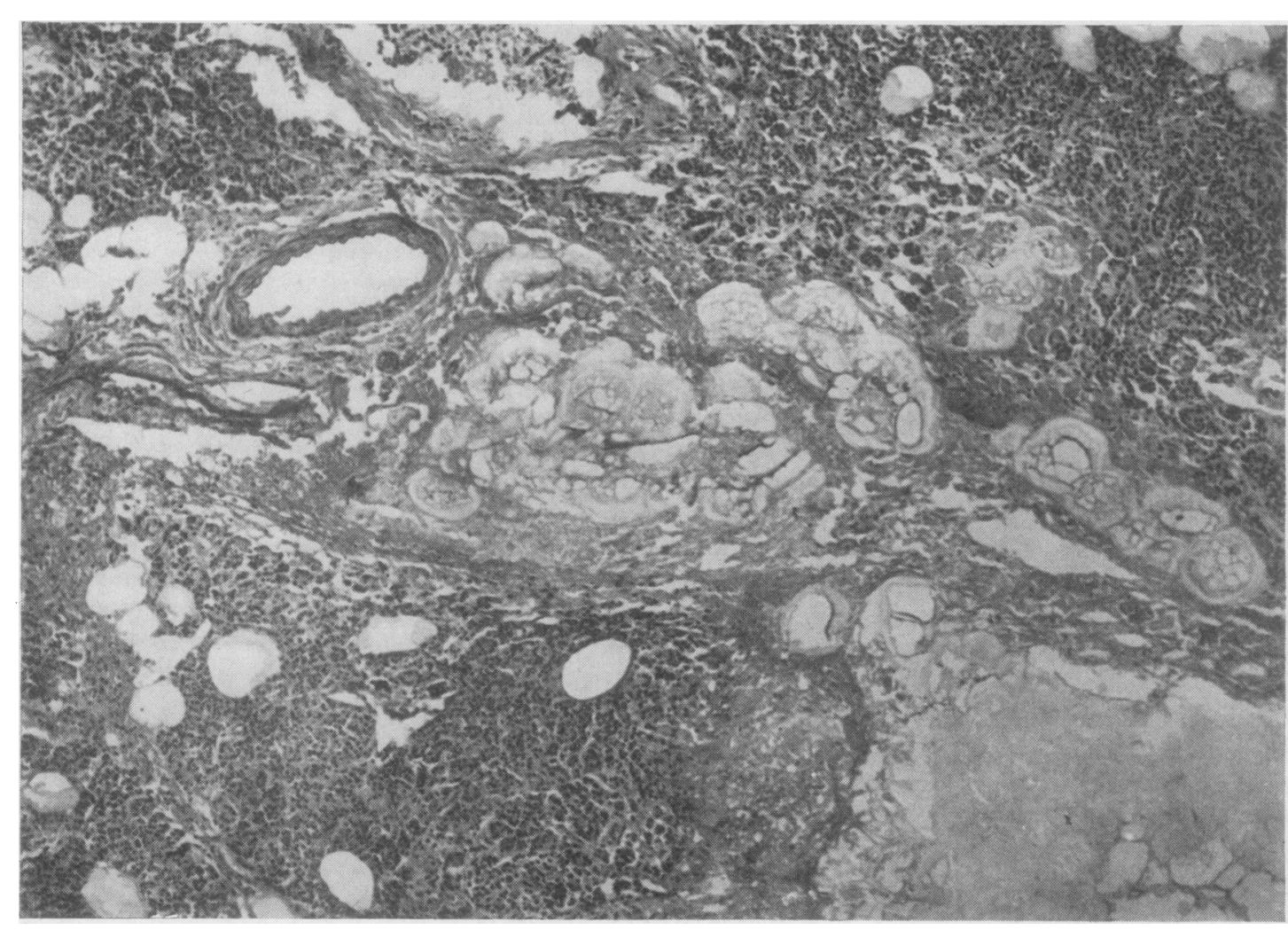

FIG. 3. Pancreas. Showing areas of necrosis of gland and of fat. Haematoxylin and eosin. $\times 185$.

Another section revealed complete necrosis with bile staining of the mucosa ; again the muscular layers were normal.

The vessels in the supplying mesentery were normal but with fat necrosis.

The pancreas showed a marked haemorrhagic pancreatitis with fat necrosis (Fig. 3).

There was necrosis of the proximal tubules of the kidneys.

The papillary muscle showed a diffuse interstitial fibrosis with recent early necrotic change of the hypertrophied muscle fibres.

The liver showed chronic venous congestion with much necrosis of the centrilobular zone.

\section{DISCUSSION}

Infarction of the small intestine is usually associated with occlusion of either the superior mesenteric artery or vein, and the full thickness of the bowel wall is usually involved. Boyd (1947) recognized a variant where the mucosa alone was infarcted and haemorrhagic, the muscle coat escaping, and no obstructive lesion of the vessels could be found.
In recent years this condition has become well $\stackrel{0}{\otimes}$ known, and Berger and Byrne (1961) reported that of 110 necropsies performed on patients with 3 intestinal necrosis between 1945 and 1956, 23 had no evidence of arterial or venous obstruction, and in 21 of these decompensated heart disease was present. These authors concluded that in congestive cardiac failure the compensatory splanchnic constriction may be severe enough to cause bowel gangrene. Marston (1962) recognized its non- or thrombotic nature and attributed the lesions to $N$ 'shock' and enumerated a variety of antecedent N conditions, including dental extractions, abdominal surgery, myocardial infarction, and aortic incompetence. McGovern and Goulton (1965) described 33 cases collected over 14 years, and suggested $\stackrel{\mathscr{D}}{\oplus}$ that pre-existing ischaemia of the gut is a predisposing cause and hypotension the precipitating factor in the acute changes. Many of their cases followed myocardial infarction.

This condition has also been recorded after open-heart surgery. Robertson and Dodds (1964) 8 described two cases, one oscurring after repair of 
and one case after replacement of an incompetent aortic valve. The first patient suffered severe haemorrhage followed by cardiac arrest. Although resuscitation was achieved, the patient died five days later with massive infarction of the gut which the authors regarded as due to 'spasm' of the mesenteric arterioles. The second patient, after a short and apparently satisfactory bypass, developed abdominal pains and distension, with the passage of tarry stools, and laparotomy revealed necrosis of the gut which demanded resection of all but $4 \frac{1}{2}$ in. of the small intestine. The patient survived. Similar symptoms and signs in a third patient after aortic valve replacement were presumed to be due to the same condition. These authors suggested that the development of the intestinal lesion in their first patient was due to ischaemia from vascular spasm following postoperative haemorrhage and irreversible shock; a search of the mesenteric vessels had revealed no embolism nor thrombus. Their second patient did not suffer haemorrhage or shock, and the vascular spasm in this case was stated to have been precipitated by a sudden change in pulse pressure following correction of aortic insufficiency. They recommended coeliac plexus block, as a preventive measure, by continuous retroperitoneal infusion of procaine during operation for repair of the seriously incompetent aortic valve. In a total of 72 aortic valve replacements we have encountered this condition only once (case 5), but in a total of 78 mitral valve replacements it has occurred in four patients.

The occurrence of haemorrhagic necrosis of the intestine in our cases suggested microembolism as a possible cause in the light of the well-documented evidence of embolism by fat (Caguin and Carter, 1963 ; Evans and Wellington, 1964 ; Allardyce, Yashida, and Ashmore, 1966), gas (Allen, 1963), antifoam 'A' (Yates, Cassie, Dark, Jack, and Ridell, 1959; Penry, Cordell, Johnson, and Netsky, 1960 ; Smith, 1960 ; Harington, 1961 ; and Helmsworth, Gall, Perrin, Brayley, Flege, Kaplan, and Keirlie, 1963), and calcium (Allen, 1963). In two cases injection of the arterial arcade with radio-opaque material failed to demonstrate obstruction that could have been missed on gross inspection. In cases 1,3 , and 5 there were only occasional fat emboli in the kidneys. We have seen severe fat embolism of the renal glomeruli, brain, and myocardium in other patients similarly perfused, but in these the gut was normal, and this, together with the failure to demonstrate fat embolism in the splanchnic vessels in our cases of haemorrhagic intestinal necrosis, had led us to exclude this as the cause. Antifoam ' $A$ ' embolism was excluded by examination of material under polarized light. Gas embolism was difficult to exclude with certainty, but it seemed unlikely that the process would affect the gut to the exclusion of other organs, especially the brain (a feature of the patients was recovery of consciousness). Further, in two patients in our perfusion series, not recorded here, in whom air was known to have entered the arterial system during perfusion, and who died without regaining consciousness, haemorrhagic intestinal necrosis did not occur. In one of our patients (case 3) there was evidence of fibrin thrombi in the splanchnic arterioles, but no evidence of such thrombi in the glomeruli, and the thrombosis in the splanchnic vessels was therefore considered to be the result and not the cause of the necrosis. Micro-embolism having been excluded, it was noted that our five cases had one feature in common-namely, the occurrence of hypotension, with or without hypovolaemiaand in this respect resembled the first case described by Robertson and Dodds (1964). In case 1 a period of marked hypotension with high central venous pressure indicated myocardial failure and low cardiac output, and this was succeeded by a period when the central blood pressure was maintained by the continuous infusion of adrenaline. In case 2 perfusion pressure was low, with inadequate flow from the pump oxygenator, and after perfusion marked peripheral vasoconstriction was evident, pulses being impalpable despite a satisfactory aortic blood pressure. Exsanguination in case 3 produced vasoconstriction of a severe order, which was not relieved. The fourth patient suffered severe haemorrhage and hypotension after bypass, and the final patient exhibited the syndrome of 'low cardiac output'. In all the circulation was gravely impaired and all exhibited some degree of renal tubular necrosis. Cerebral ischaemia had occurred in case 5 , as evidenced by the presence of 'geographic areas' in the brain (Brierley, 1963).

Hypovolaemia and hypotension are common causes of the 'shock syndrome'. When this condition occurs in man, early and adequate fluid replacement is curative. However, if replacement is late or inadequate, although the central blood pressure may be temporarily restored, three organs-the liver, intestines, and kidneys-may experience no sustained improvement in blood flow and may exhibit pathological lesions even after apparently successful therapy (Zweifach, 1965). Zweifach postulated that if the state of 
shock continues untreated the splanchnic vessels may lose the power to respond to normal stimuli and remain in spasm until a fatal outcome ensues, although for a time the cerebral and coronary circulations may be sustained at the expense of the 'target organs' described. It has also been suggested (Lillehei, Longerbeam, Bloch, and Manax, 1964) that irreversibility of the shock syndrome begins when local metabolic changes occur, the precapillary sphincters dilating in response to hypoxic acidosis while the less sensitive postcapillary sphincter remains in spasm. The capillaries are then exposed to and are damaged by an increased hydrostatic pressure: transudation follows, aggravating hypovolaemia.

In experimental shock in dogs, haemorrhagic intestinal necrosis is an almost invariable finding (Lillehei, 1957), and death in a 'shock-like' state was produced in animals, by continuous infusion of adrenaline, despite a rise in the central blood pressure (Erlanger and Gasser, 1919).

It is therefore suggested that in our patients periods of hypovalaemia, or hypotension, or a combination of both, resulted in irreversible changes in the splanchnic vasculature, giving rise to haemorrhagic intestinal necrosis. However, it is to be noted that in another series of patients undergoing perfusion and open-heart surgery we have encountered evidence of cerebral ischaemia in the occurrence of 'geographic areas' of neuronal loss, and in others acute tubular necrosis, with no abnormality of the gut. Thus there may be localizing factors in certain cases of 'shock'. Lillehei and MacLean (1959) have stressed the illogicality of the prolonged use of vasopressors in a condition already characterized by vasoconstriction, and a recent review of irreversible shock (Lancet, 1965) discussed the place of isoprenaline, phenoxybenzamine, and cortisone in preventing and relieving vasoconstriction. All our patients were treated with adrenaline, which may have been an accessory factor in aggravating the splanchnic spasm, and it is now our practice to use isoprenaline rather than adrenaline in circulatory insufficiency. Another possible factor is the pooling of blood in the splanchnic vasculature (homologous blood syndrome (Litwak, Slonim, Wisoff, and Gadboys, 1963) ) during and after perfusion, or similar pooling following elevation of central venous pressure from whatever cause (Davidson and Farthman, 1965). We have no certain evidence that either factor operated in our cases.

Haemorrhagic intestinal necrosis is evidently not specific to perfusion and open-heart surgery, but patients undergoing this may be particularly susceptible as the cardiac disease has often been responsible for a low cardiac output for a considerable time.

In addition to haemorrhagic necrosis of the small bowel present in the five patients, two other complications were also encountered. A local dissecting aneurysm arising from the site of femoral artery cannulation, causing difficulty in perfusion as well as a cause of unsuspected blood loss in its own right, has been previously recorded (van der Woude and Iticovicci, 1962). Its occurrence in case 3 was the reason for the unsatisfactory perfusion, and the fear of this possibility has caused many centres to abandon femoral artery cannulation. A more unusual complication was that of haemorrhagic pancreatitis in case 5 . We have found no previous report of this following open-heart surgery; but it has been recorded following other operations, most frequently after gastric resections, cholecystectomy, and operation on the extrahepatic biliary tree, when manipulation of the pancreas or interference with its blood supply may occur (Ensand, 1966). It has also been recorded as a complication in patients recovering after external cardiac massage (Cowan, 1966) when local trauma was considered an important factor. This is unlikely in our patient as the cardiac massage was terminal. Baer and Neu (1966) considered intravascular coagulation to be important in the pathogenesis of acute pancreatitis complicating acute hyper-parathyroid crises involving an increase in $\mathrm{Ca}^{+}$ions as a probable cause of the intravascular clotting. Although this would be an attractive hypothesis following open-heart surgery where intramuscular coagulation is a known hazard, it was not noted in the glomeruli, 의 iliac or pancreatic vessels in our patient with acute pancreatitis. Small foci of pancreatic fat $\frac{9}{3}$ necrosis have been seen in several patients follow- $\frac{T}{O}$ ing perfusion and are possibly more common than is generally appreciated. In our patient we feel o that the pancreatitis was due to poor tissue per- $N$ fusion in the post-operative phase, the pancreas ${ }_{N}$ suffering with the kidneys, brain, and small intes- $\omega$ tine. The pancreas may share in splanchnic pool- ing as it is part of the portal circulation, and the importance of venous stasis in the production of $\mathbb{D}$ pancreatic necrosis has been shown by Anderson? (1963).

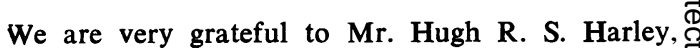
Mr. T. H. L. Rosser, and Mr. Dillwyn M. E. Thomas for allowing us to study their cases, to Mr. F. Midgeley for the photographs, and to Miss P. Morse and Miss $\mathbf{P}$. Edwards for secretarial assistance. 


\section{REFERENCES}

Allardyce, D. B., Yashida, S. H., and Ashmore, P. G. (1966). The importance of microembolism in the pathogenesis of organ dysfunction caused by prolonged use of the pump-oxygenator. J. thorac. cardiovasc. Surg., 52, 706 .

Allen, P. (1963). Central nervous system emboli in open-heart surgery. Canad. J. Surg., 6, 332.

Anderson, M. C. (1963). Venous stasis in the transition of oedematous pancreatitis to necrosis. J. Amer. med. Ass., 183, 534.

Baer, L., and Neu, H. C. (1966). Intravascular clotting and acute pancreatitis in primary hyperparathyroidism. Ann. intern. Med., 64, 1062 .

Berger, R. L., and Byrne, J. J. (1961). Intestinal gangrene associated with heart disease. Surg. Gynec. Obstet., 112, 529.

Boyd, W. (1947). Surgical Pathology, 6th ed., p. 91. Saunders, Philadelphia and London.

Brierley, J. B. (1963). Neuropathological findings in patients dying after open-heart surgery. Thorax, 18, 291.

Caguin, F., and Carter, M. G. (1963). Fat embolization with cardiotomy with the use of cardio-pulmonary by-pass. $J$. thorac. cardiovasc. Surg., 46, 665.

Cowan, D. (1966). Pancreatitis and pulmonary haemorrhage complicating closed-chest cardiac massage. Canad. med. Ass. J., p5, 976.

Davidson, A. I. G., and Farthman, E. H. (1965). Splanchnic pooling during left-heart by-pass. Surg. Gynec. Obstet., 121, 1277.

Ensand, E. R. (1966). Acute post-operative pancreatitis. Med. Tms (N.Y.), 94, 755.

Evans, E. A., and Wellington, J. S. (1964). Emboli associated with cardio-pulmonary by-pass. $J$. thorac. cardiovasc. Surg., 48, 323.

Erlanger, J., and Gasser, J. S. (1919). Studies in secondary traumatic shock. III. Circulatory failure due to adrenalin. Amer. J. Physiol., $49,345$.

Harington, J. S. (1961). A study of the chemical composition and potential hazards of an antifoam substance used in intra-cardiac surgery. Thorax, 16, 120.
Helmsworth, J. A., Gall, E. A., Perrin, E. V., Brayley, S. A., Flege, J. B., Jr., Kaplan, S., and Keirlie, A. M. (1963). Occurrence of emboli during perfusion with an oxygenator pump. Surgery, of emboli.

Lancet (1965). Irreversible shock. Leader, 1, 255.

Lillehei, R. C. (1957). The intestinal factor in irreversible haemorrhagic shock. Surgery, 42, 1043.

_Longerbeam, J. K., Bloch, J. H., and Manax, W. G. (1964). The nature of irreversible shock: experimental and clinical observations. Ann. Surg., 160, 682.

- and MacLean, L. D. (1959). Physiological approach to successful treatment of endotoxin shock in the experimental animal. Arch. Surg., 78, 464.

Litwak, R. S., Slonim, R., Wisoff, B. G., and Gadboys, H. L. (1963). Homologous-blood syndrome during extracorporeal circulation in man. New Engl. J. Med., 268, 1377.

Marston, A. (1962). The bowel in shock: Role of mesenteric arterial disease as a cause of death in the elderly. Lancet, $2,365$.

McGovern, V. J., and Goulton, S. J. M. (1965). Ischaemic enterocolitis. Gut, 6, 213.

Penry, J. K., Cordell, A. R., Johnson, F. R., and Netsky, M. G. (1960). Cerebral embolism by antifoam $A$ in a bubble oxygenator system. An experimental and clinical study. Surgery, 47, 784.

Robertson, R., and Dodds, W. A. (1964). Mesenteric artery insufficiency complicating repair of aortic regurgitation. Canad. J. Surg., 7, 269.

Smith, W. T. (1960). Cerebral lesions due to emboli of silicone antifoam in dogs subjected to cardio-pulmonary by-pass. J. Path. Bact., 80, 9.

van der Woude, R., and Iticovicci, H. (1962). Retroperitoneal haemorrhage as a complication of femoral artery cannulation for extracorporeal circulation. J. thorac. cardiovasc. Surg., 44, 540.

Yates, P. O., Cassie, A. B., Dark, F. J., Jack, G. D., and Ridell, A. G. (1959). Detection of antifoam emboli following perfusion with a heart-lung machine. Lancet, 1, 130.

Zweifach, B. W. (1965). Aetiology of the shock syndrome. Heart Bull., 14, 21 . 